\title{
New Tools to Study Contact Activation
}

\author{
Steffen Rosén* \\ Private Practice, Molndal, Sweden
}

The recent availability of a sensitive chromogenic method approach for determination of FXla activity has been explored for designing sensitive methods for FXIla and kallikrein, both using FXa formation as the read-out. For both enzymes the assay range $1-10 \mathrm{nmol} / \mathrm{L}$ provides a resolution of about 0.8 absorbance units with a total assay time of about 20 min. For studies on activation kinetics, subsampling and extensive dilution can be performed in MES-bovine serum albumin (BSA) buffer pH 5.7 for quenching of enzyme activity and with ensuing determination of FXa generation in a chromogenic FXla method. Optionally, suitable inhibitors such as aprotinin and/or corn trypsin inhibitor may be included. The stability of FXla, FXIla, and kallikrein in MES-BSA buffer was shown to be at least $5 \mathrm{~h}$ on ice. In conclusion, the use of a sensitive chromogenic FXla method either per se or in combination with MES-BSA buffer $\mathrm{pH} 5.7$ are new and potentially valuable tools for the study of contact factor enzymes and their inhibitors. So

OPEN ACCESS

Edited by:

Joost Meijers,

University of Amsterdam,

Netherlands

Reviewed by:

Coen Maas,

University Medical Center Utrecht,

Netherlands

José Govers-Riemslag,

Maastricht University Medical Center,

Netherlands

*Correspondence:

Steffen Rosén

steffen.rosen@rossix.com

Specialty section:

This article was submitted to Hematology, a section of the

journal Frontiers in Medicine

Received: 27 September 2016

Accepted: 03 November 2016

Published: 22 November 2016

Citation:

Rosén S (2016) New Tools to Study Contact Activation.

Front. Med. 3:58.

doi: 10.3389/fmed.2016.00058 far, dose-response studies of FXIla and kallikrein have been limited to purified systems, and hence more data are required to learn whether these new methods might or might not be applicable to the determination of FXIla and kallikrein activities in plasma.

Keywords: FXIa, FXIla, kallikrein, methods, chromogenic

\section{INTRODUCTION}

The contact activation pathway, involving factor XII (FXII), prekallikrein (PK), high molecular weight kininogen (HK), and factor XI (FXI) displays complex interactions and is involved in both coagulation and inflammation [for reviews, see Ref. $(1,2)]$. Much research has been devoted to this area during the last 20 years, partly due to the findings that FXI can be activated on the platelet surface by thrombin (3-8) and also due to the more recent interest in anti-FXI antibodies and FXI antisense nucleotides as antithrombotic agents (9-13).

In vivo as well as for in vitro studies on plasma, contact activation is surface-bound, i.e., contact factors assemble on a negatively charged surface with the initial step being binding and autoactivation of FXII. PK and FXI bind to the surface through HK. In vitro, this is utilized in any APTT-based method, and the negatively charged surface is provided as a constituent in the APTT reagent, typically as some variant of silica or as ellagic acid.

Studies performed more than 40 years ago demonstrated that surface-bound FXII and FXI are much more effectively activated than in solution and also that $\mathrm{HK}$ is a cofactor to such activation, however not a mandatory requirement (14-16).

More recently, sensitive chromogenic methods for FXIa have been developed and made available as commercial kits $(17,18)$. These products were originally developed for detection of trace amounts of FXIa as contaminant in pharmaceutical products such as intravenous immunoglobulins. However, the chromogenic FXIa method has also been applied for investigation of FXI activation 
during contact activation on analysis of a one-stage method for potency assignment of the extended half-life rFIX product N9-GP (19). Here, subsampling and dilution into a low $\mathrm{pH}$ buffer was used to quench further activation. This combined approach has now been explored for designing sensitive methods for FXIIa and kallikrein. Part of this work was presented at the ISTH/SSC meeting in May 2016 (20).

\section{MATERIALS AND METHODS}

Chromogenic kit Rox Factor XIa (Rossix AB, Molndal, Sweden) was used for photometric determination of FXIa activity. The kit comprises two lyophilized reagents, one containing human factor IX, human factor VIII, and calcium chloride and the other containing human factor $\mathrm{X}$, bovine thrombin, phospholipids, and calcium chloride. The chromogenic FXa substrate Carboxybenzyl-D-Arg-Gly-Arg-pNA is included in the kit as a liquid solution. The limit of quantitation in the assay is about $0.02 \mathrm{mIU} / \mathrm{mL}$, calibrated vs. the WHO first Int Std FXIa (ref $13 / 100)$. This corresponds roughly to $0.01 \mathrm{pmol} / \mathrm{L}$ of FXIa.

Bovine serum albumin (BSA) was approved for use as a bulking agent of coagulation proteins (Rossix $\mathrm{AB}$ ).

The coagulation proteins human FXI, human FXIa, human FXII, human $\alpha$ FXIIa, human PK, human plasma kallikrein (kallikrein), and corn trypsin inhibitor (CTI) were all from Enzyme Research Laboratories (South Bend, IN, USA).

Frozen human normal pooled plasma (NPL) was from Precision Biologics (Dartmouth, Canada).

Activated partial thromboplastin reagent APTT SP was from Instrumentation Laboratory, Bedford, MA, USA.

Bovine lung aprotinin was from Sigma-Aldrich, St Louis, MI, USA.

Tris(hydroxymethyl)aminomethane (Tris), Tris hydrochloride, 2-(N-morpholino)ethanesulfonic acid (MES), and sodium chloride were from Sigma-Aldrich. All chemicals were of reagent grade.

MES-BSA buffer was prepared to contain $0.05 \mathrm{~mol} / \mathrm{L} \mathrm{MES} \mathrm{pH}$ 5.7, 0.05 M NaCl, 0.2\% BSA.

Also, $0.1 \mathrm{~mol} / \mathrm{L}$ Tris buffer $\mathrm{pH} 8.3\left(25^{\circ} \mathrm{C}\right)$ was used for neutralization in assays with samples in MES buffer.

Dilution of coagulation proteins was made in $0.05 \mathrm{~mol} / \mathrm{L}$ Tris buffer $\mathrm{pH} 7.5\left(25^{\circ} \mathrm{C}\right), 0.1 \mathrm{~mol} / \mathrm{L} \mathrm{NaCl}, 1 \% \mathrm{BSA}$, denoted working buffer solution (WBS).

\section{Determination of FXla Activity}

FXIa activity was determined with the Rox Factor XIa kit method. The activity is expressed in milli-international units per milliliter.

\section{Determination of FXIla Activity through Generation of FXIa}

At different doses, $25 \mu \mathrm{L}$ FXIIa was mixed in microplate wells with $50 \mu \mathrm{L}$ FXI and $25 \mu \mathrm{L}$ WBS, whereafter $25 \mu \mathrm{L}$ APTT SP was added to provide a contact activation surface. Final concentrations were 0, 1-10 nmol/L of FXIIa, and $40 \mathrm{nmol} / \mathrm{L}$ of FXI.

The activation of FXI was allowed to proceed for $6 \mathrm{~min}$ at $37^{\circ} \mathrm{C}$ followed by addition of $50 \mu \mathrm{L}$ CTI (final concentration $0.35 \mu \mathrm{M}$ ) for inactivation of FXIIa. After a further incubation for $2 \mathrm{~min}$ at $20-25^{\circ} \mathrm{C}$ to ensure complete inactivation of FXIIa, simultaneous consecutive dilutions of all incubation mixtures were made in MES-BSA buffer in microplate wells to reach a 250-fold dilution.

Then, generated FXIa activity was determined with the Rox Factor XIa kit method and with supplementation of $0.1 \mathrm{~mol} / \mathrm{L}$ Tris buffer $\mathrm{pH} 8.3$ for neutralization.

\section{Determination of Kallikrein Activity through Generation of FXIa via FXII Activation}

At different doses, $25 \mu \mathrm{L}$ kallikrein was mixed in microplate wells with $50 \mu \mathrm{L}$ FXI, $8 \mu \mathrm{L}$ FXII, and $25 \mu \mathrm{L}$ WBS whereafter $25 \mu \mathrm{L}$ APTT SP was added to provide a contact activation surface. Final concentrations were $0,1-10 \mathrm{nmol} / \mathrm{L}$ of kallikrein, $40 \mathrm{nmol} / \mathrm{L}$ of FXI, and $93 \mathrm{nmol} / \mathrm{L}$ of FXII.

The activation of FXII and FXI was allowed to proceed for $6 \mathrm{~min}$ at $37^{\circ} \mathrm{C}$ followed by addition of $50 \mu \mathrm{L}$ CTI (final concentration $4 \mu \mathrm{g} / \mathrm{mL}$ ) for inactivation of FXIIa. After a further incubation for $2 \mathrm{~min}$ at $20-25^{\circ} \mathrm{C}$ to ensure complete inactivation of FXIIa, simultaneous consecutive dilutions of all incubation mixtures were made in MES-BSA buffer in microplate wells to reach 50 - and 200-fold dilutions.

Then, generated FXIa activity was determined with the Rox Factor XIa kit method and with supplementation of $0.1 \mathrm{~mol} / \mathrm{L}$ Tris buffer $\mathrm{pH} 8.3$ for neutralization.

\section{Stability Tests in MES-BSA Buffer}

The above biological activity methods for FXIa, FXIIa, and kallikrein were utilized to study the stability of these enzymes in MES-BSA buffer. WBS was first diluted fourfold in water to decrease its buffering capacity and then used for suitable predilution of each enzyme. These were subsequently 21 -fold diluted in ice cold MES-BSA buffer and kept on ice. Also, $50 \mu \mathrm{L}$ aliquots were withdrawn from each enzyme solutions at time points 0 , $1,2,3,4$, and $5 \mathrm{~h}$ and immediately frozen at $-70^{\circ} \mathrm{C}$ and kept at $-70^{\circ} \mathrm{C}$ until analysis. The biological activities of FXIa, FXIIa, and kallikrein were then determined as described above.

\section{Determination of Stability of FXla Added to Plasma or Generated in Plasma via Contact Activation Contact-Activated FXI}

Three hundred and thirty microliter NPL was contact activated with $165 \mu \mathrm{L}$ APTT SP for $5 \mathrm{~min}$, followed by addition of $20 \mu \mathrm{L}$ of CTI (final concentration $4 \mu \mathrm{g} / \mathrm{mL}$ ) and $20 \mu \mathrm{L}$ of aprotinin (final concentration $350 \mathrm{KIU} / \mathrm{mL}$ ) to inhibit FXIIa and kallikrein, respectively. The concentration used of aprotinin inhibited $>98 \%$ of kallikrein activity and about $70 \%$ of FXIa activity.

A first subsampling was then immediately made of $10 \mu \mathrm{L}$ into 3 mL MES-BSA buffer (301-fold dilution) followed by further subsamplings after $30 \mathrm{~s}$ and up to $20 \mathrm{~min}$.

\section{FXla Spiked into Plasma}

Twenty microliter FXIa was added to $480 \mu \mathrm{L}$ human normal plasma and subsampling was made of $10 \mu \mathrm{L}$ into $3 \mathrm{~mL}$ MES-BSA 


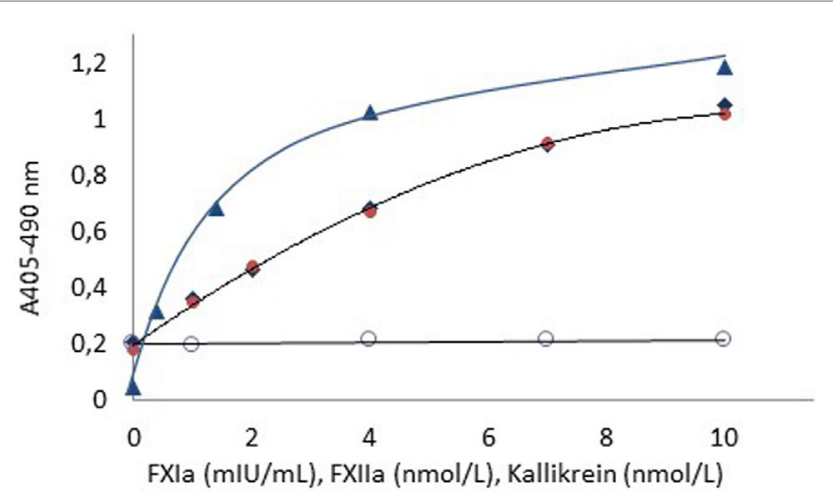

FIGURE 1 | Dose-response curves for FXla ( $\mathbf{\Delta}$ ), FXIla ( ), and kallikrein (O) using APTT SP as contact surface provider. The dose-response curve for kallikrein in the absebce of APTT SP (O) is also shown. The higher blank value for FXIla and kallikrein as compared to FXIa is due to presence of FXla in the FXI zymogen preparation.

buffer after $30 \mathrm{~s}$ followed by further subsamplings up to $20 \mathrm{~min}$. The zero time sample was obtained by adding $10 \mu \mathrm{L}$ of a 25 -fold lower FXIa concentration directly to $3 \mathrm{~mL}$ MES-BSA buffer.

The FXIa activity was then determined as described above.

\section{RESULTS}

\section{Dose-Response Curves for FXIa, FXIla, and Kallikrein}

Figure 1 shows dose-response curves for FXIa (1-10 mIU/mL), FXIIa (1-10 nmol/L), and kallikrein (1-10 nmol/L) using FXa formation as the read-out with the Rox Factor XIa kit and hence expressing biological functional activities of these enzymes.

For all enzymes, the resolution was at least 0.8 absorbance units in the tested ranges. The blank activity of about 0.2 absorbance units noticed for the FXIIa and kallikrein curves is due to contaminating FXIa in the used FXI zymogen preparation.

\section{Stability of FXIa, FXIla, and Kallikrein in MES-BSA Buffer}

The stability of FXIa, FXIIa, and kallikrein was determined after storage for up to $5 \mathrm{~h}$ in ice cold MES-BSA buffer $\mathrm{pH} 5.7$ using the above methods. For all enzymes, the recovery of activity was between 95 and $102 \%$ of the initial activity during the 5-h storage time. Similar results were also obtained from determination of enzyme activities with direct hydrolysis of suitable chromogenic substrates (data not shown).

\section{Stability of FXla Added to Plasma or Generated in Plasma via Contact Activation}

Figure 2 shows that about $85 \%$ of the FXIa activity was lost 6 min after spiking of FXIa to plasma, whereas about $96 \%$ of the FXIa activity remained after 6 min when generated during contact activation. The activity then fell gradually but was still above $80 \%$ after 20 min storage.

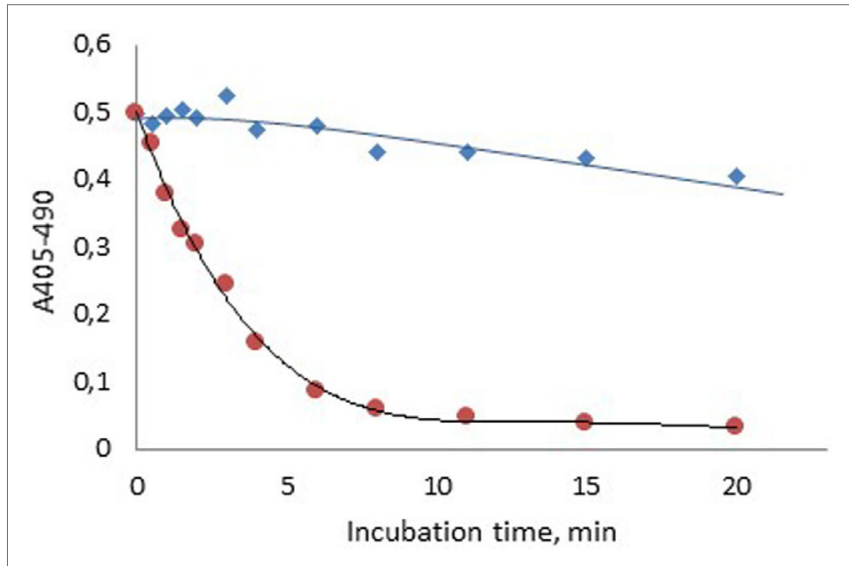

FIGURE 2 | Stability of human FXla in normal plasma after formation via contact activation with APTT SP ( $)$ or after spiking into plasma (

\section{DISCUSSION}

The high sensitivity of the chromogenic FXIa method ( $0.02 \mathrm{mIU} /$ $\mathrm{mL}$ or about $0.01 \mathrm{pmol} / \mathrm{L}$ ) allows extensive sample dilutions to minimize or eliminate interferences from sample matrices. This has been utilized in the present study for designing biological activity methods also for FXIIa and kallikrein as shown in Figure 1. Such methods reflect the functional, biological activity in contrast to direct amidolytic methods in which suitable chromogenic substrates are directly cleaved by FXIa, FXIIa, and kallikrein. Such methods may not always reflect the biological activity as is illustrated, e.g., by $\gamma$-thrombin, which cleaves low molecular chromogenic substrates but splits its natural substrate fibrinogen very poorly (21). Furthermore, enzymes in complex with $\alpha_{2}$-macroglobulin usually cleave chromogenic substrates but not natural protein substrates (22-25).

The FXIIa and kallikrein methods should be regarded as "principle approaches," demonstrating their feasibility but not claimed to be optimized. Thus, doubling the FXII zymogen concentration in the kallikrein method gave a significant increased rate of FXII activation by kallikrein, and hence an increase in FXIa generation resulting in about 50\% higher FXa formation (data not shown). The utilized concentration range, $1-10 \mathrm{nmol} / \mathrm{L}$ for FXIIa and kallikrein, corresponds to about $0.25-2.5 \%$ and $0.18-1.8 \%$ of the plasma zymogen concentrations of FXII and PK, respectively. The methods may tentatively be further amplified by including also the prothrombinase complex in the final step and thus use thrombin formation rather than generation of FXa as the read-out.

Common for all three methods is the use of a contact activator (APTT SP) as a surface provider and trigger of activation. Importantly, HK does not have to be present in agreement with earlier findings (16).

It is also worth mentioning that the used concentrations of CTI and aprotinin only cause $\leq 5 \%$ inhibition of the FXa generation (data not shown).

The demonstrated stability of FXIa, FXIIa, and kallikrein in MES-BSA buffer pH 5.7 may be conveniently utilized in, e.g., studies on activation kinetics where subsampling and extensive 
dilutions in MES-BSA buffer followed by chromogenic FXIa determination provides a sensitive and robust tool for such studies (19).

This combined concept was also utilized in the present study to demonstrate a pronounced difference in FXIa stability when formed during contact activation in plasma as compared to addition of FXIa in plasma (Figure 2). The higher stability of FXIa in the former case is due to protection of FXIa by HK in the contact factor complex (26). The slow inhibition of generated FXIa, with about $20 \%$ inhibition after $20 \mathrm{~min}$ is caused by several protease inhibitors, primarily C1-esterase inhibitor, $\alpha_{2}$-antiplasmin, and $\alpha_{1}$-antitrypsin (27).

A further illustration on the advantage with the high sensitivity of the FXIa method is the use of aprotinin for efficient inhibition of kallikrein. Even though the used concentration, $350 \mathrm{KIU} / \mathrm{mL}$, of aprotinin caused about 70\% inhibition of FXIa, sufficient FXa generation in the chromogenic FXIa method was easily obtained.

In conclusion, the use of a sensitive chromogenic FXIa method either per se or in combination with MES-BSA buffer pH 5.7 may be valuable tools for study of contact factor enzymes and their inhibitors.

The system may tentatively be further amplified by using thrombin formation rather than generation of FXa as the end-point.

\section{SUMMARY}

The recent availability of a sensitive chromogenic method approach for the determination of FXIa activity has been

\section{REFERENCES}

1. Cadena RA, Wachtfogel YT, Colman RW. Contact activation pathway: inflammation and coagulation. 3rd ed. In: Colman RW, Hirsh J, Marder VJ, Salzman EW, editors. Hemostasis and Thrombosis: Basic Principles and Clinical Practice. Philadelphia, USA: Lippincott Co (1994). p. 219-37.

2. Emsley J, McEwan PA, Gailani D. Structure and function of factor XI. Blood (2010) 115:2569-77. doi:10.1182/blood-2009-09-199182

3. Gailani D, Broze GJ Jr. Factor XI activation in a revised model of blood coagulation. Science (1991) 253:909-12. doi:10.1126/science.1652157

4. Naito K, Fujikawa K. Activation of human blood coagulation factor XI independent of factor XII. Factor XI is activated by thrombin and factor XIa in the presence of negatively charged surfaces. JBiol Chem (1991) 266:7353-8.

5. Von dem Borne PA, Meijers JC, Bouma BN. Feedback activation of factor $\mathrm{XI}$ by thrombin in plasma results in additional formation of thrombin that protects fibrin clots from fibrinolysis. Blood (1995) 86:3035-42.

6. Yun TH, Baglia FA, Myles T, Navaneetham D, Lopez JA, Walsh PN, et al. Thrombin activation of factor $\mathrm{XI}$ on activated platelets requires the interaction of factor XI and platelet glycoprotein $\mathrm{Ib}$ alpha with thrombin anion-binding exosites I and II, respectively. J Biol Chem (2003) 278:48112-9. doi:10.1074/ jbc.M306925200

7. Pedicord DL, Seiffert D, Blat Y. Feedback activation of factor XI by thrombin does not occur in plasma. Proc Natl Acad Sci U S A (2007) 104:12855-60. doi:10.1073/pnas.0705566104

8. Maas C, Meijers JCM, Marquart JA, Bakhtiari K, Weeterings C, de Groot $\mathrm{PG}$, et al. Activated factor $\mathrm{V}$ is a cofactor for the activation of factor XI by thrombin in plasma. Proc Natl Acad Sci U S A (2010) 107:9083-7. doi:10.1073/ pnas. 1004741107

9. Zhang H, Löwenberg EC, Crosby JR, MacLeod AR, Zhao C, Gao D, et al. Inhibition of the intrinsic coagulation pathway factor XI by antisense oligonucleotides: a novel antithrombotic strategy with lowered bleeding risk. Blood (2010) 116:4684-92. doi:10.1182/blood-2010-04-277798 explored for designing sensitive methods for FXIIa and kallikrein, both using FXa formation as the read-out. For both enzymes the assay range $1-10 \mathrm{nmol} / \mathrm{L}$ provides a resolution of about 0.8 absorbance units with a total assay time of about $20 \mathrm{~min}$.

For studies on activation kinetics, subsampling and extensive dilution can be performed in MES-BSA buffer $\mathrm{pH} 5.7$ for quenching of enzyme activity, optionally including aprotinin and/or CTI, and with ensuing determination of FXa generation in the chromogenic FXIa method.

The stability of FXIa, FXIIa, and kallikrein in MES-BSA buffer was shown to be at least $5 \mathrm{~h}$ on ice.

In conclusion, the use of a sensitive chromogenic FXIa method either per se or in combination with MES-BSA buffer $\mathrm{pH} 5.7$ are new and potentially valuable tools for study of contact factor enzymes and their inhibitors. It should be noted that these assays have not been evaluated for the determination of FXIIa and kallikrein in patients' plasma.

\section{AUTHOR CONTRIBUTIONS}

SR designed and performed the experiments and wrote the manuscript.

\section{ACKNOWLEDGMENTS}

Pia Bryngelhed is acknowledged for skillful technical assistance.

10. van Montfoort ML, Knaup VL, Marquart JA, Bakhtiari K, Castellino FJ, Hack CE, et al. Two novel inhibitory anti-human factor XI antibodies prevent cessation of blood flow in a murine venous thrombosis model. Thromb Haemost (2013) 110:1065-73. doi:10.1160/TH13-05-0429

11. Crosby JR, Marzec U, Revenko AS, Zhao C, Gao D, Matafonov A, et al. Antithrombotic effect of antisense factor XI oligonucleotide treatment in primates. Arterioscler Thromb Vasc Biol (2013) 33:1670-8. doi:10.1161/ ATVBAHA.113.301282

12. Büller HR, Bethune C, Bhanot S, Gailani D, Monia BP, Raskob GE, et al. Factor $\mathrm{XI}$ antisense oligonucleotide for prevention of venous thrombosis. $N$ Engl J Med (2015) 372:232-40. doi:10.1056/NEJMoa1405760

13. Gailani D, Bane CE, Gruber A. Factor XI and contact activation as targets for antithrombotic therapy. J Thromb Haemost (2015) 13:1383-95. doi:10.1111/ jth.13005

14. Griffin JH. Role of surface in surface-dependent activation of Hageman factor (blood coagulation factor XII). Proc Natl Acad Sci U S A (1977) 75:1998-2002. doi:10.1073/pnas.75.4.1998

15. Griffin JH, Cochrane CG. Identification of prekallikrein and high molecular weight kininogen as a complex in human plasma. Proc Natl Acad Sci U S A (1976) 73:2554-8. doi:10.1073/pnas.73.8.2554

16. Fujikawa K, Heimark RL, Kurachi K, Davie EW. Activation of bovine factor XII (Hageman factor) by plasma kallikrein. Biochemistry (1980) 19:1322-30. doi:10.1021/bi00548a010

17. Kit package insert Biophen Factor XIa, Hyphen, BioMed. Available from: http://www.hyphen-biomed.com

18. Kit package insert Rox Factor XIa, Rossix AB. Available from: http://www. rossix.com

19. Rosén P, Rosén S, Ezban M, Persson E. Overestimation of N-glycoPEGylated factor IX activity in a one-stage clotting assay owing to silica-mediated premature conversion to activated factor IX. J Thromb Haemost (2016) 14:1420-7. doi:10.1111/jth.13359

20. Rosén S. New Tools to Study Contact Activation. 62 ${ }^{\text {nd }}$ ISTH/SSC Meeting, Session Factor XI and the Contact System. Montpellier, France (2016). 
21. Witting JI, Millar TM, Fenton JW II. Human alpha- and gamma thrombin specificity with tripeptide p-nitroanilide substrates under physiologically relevant conditions. Thromb Res (1987) 46:567-74. doi:10.1016/0049-3848(87)90157-5

22. Barret AJ, Starkey PM. The interaction of $\alpha_{2}$-macroglobulin with proteinase. Biochem J (1973) 133:709-15.

23. Harpel PC. Studies on human plasma $\alpha_{2}$-macroglobulin enzyme interactions. Evidence for proteolytic modification of the subunit chain structure. J Exp Med (1973) 138:508-21. doi:10.1084/jem.138.3.508

24. Amundsen E, Gallimore MJ, Aasen AO, Larsbraaten M, Lyngaas K. Activation of human plasma prekallikrein: influence of activators, activation time and inhibitors. Thromb Res (1978) 13:625-36. doi:10.1016/0049-3848(78)90152-4

25. Gallimore M, Friberger P. Chromogenic substrate assays for prekallikrein, kallikrein inhibitor and "kallikrein-like" activity. Thromb Res (1982) 25:293-8. doi:10.1016/0049-3848(82)90248-1

26. Scott CF, Schapira M, James HL, Cohen AB, Colman RW. Inactivation of factor XIa by plasma protease inhibitors. Predominant role of $\alpha 1$-protease inhibitor and protective effect of high molecular weight kininogen. J Clin Invest (1982) 69:844-52. doi:10.1172/JCI110524

27. Wuillemin WA, Minnema M, Meijers JCM, Roem D, Eerenberg AJM, Nuijens JH, et al. Inactivation of factor XIa in human plasma assessed by measuring factor XIa-protease Inhibitor complexes: major role for Cl-Inhibitor. Blood (1995) 85:1517-26.

Conflict of Interest Statement: SR is a consultant to Rossix AB.

Copyright (C) 2016 Rosén. This is an open-access article distributed under the terms of the Creative Commons Attribution License (CC BY). The use, distribution or reproduction in other forums is permitted, provided the original author(s) or licensor are credited and that the original publication in this journal is cited, in accordance with accepted academic practice. No use, distribution or reproduction is permitted which does not comply with these terms. 